\title{
Prevalence of Metabolic Syndrome in Overweight and Obese Filipino Adolescents Based on the IDF Definition
}

\author{
Sioksoan Chan Cua \\ Department of Pediatrics \\ College of Medicine and Philippine General Hospital \\ University of the Philippines Manila
}

\begin{abstract}
Objective. This study determined the prevalence of metabolic syndrome (MetS) in overweight and obese Filipino adolescents.

Methodology. A total of 350 overweight and obese Filipino adolescents (aged 10 to 18 years, 206 males and 144 females) referred to pediatric endocrine clinics in Metro Manila were included. Weight, height, waist and blood pressure were measured and fasting lipid profiles, blood glucose and insulin were determined. MetS is defined as presence of three out of five clinical features: central obesity, hyperglycemia, hypertriglyceridemia, low HDL-C level and hypertension. The prevalence of MetS was determined based on the International Diabetes Federation (IDF) definition.

Results. The overall prevalence of MetS in overweight and obese adolescents was $19 \%$. Among participants, $98 \%$ had abdominal adiposity, $25 \%$ hypertension, $24 \%$ hypertriglyceridemia, $17 \%$ low HDL and $12 \%$ hyperglycemia; $67 \%$ had hyperinsulinemia $(>15 \mathrm{uU} / \mathrm{ml}$ ) and $70 \%$ had insulin resistance based on HOMA-IR ( $\geq 3)$. Among those with MetS, $14 \%$ had 3 components and $5 \%$ had 4 components; the prevalence of hyperinsulinemia and insulin resistance rose to $79 \%$ and $90 \%$, respectively, with high mean levels of serum insulin $(31.3 \mu \mathrm{U} / \mathrm{ml})$ and HOMA-IR $(7.7)$.
\end{abstract}

Conclusion. Overweight and obese adolescents are at risk to develop MetS. The prevalence of hyperinsulinemia and insulin resistance is high.

Keywords: Metabolic syndrome, obesity, overweight, adolescent, Filipino, hypertension, hyperglycemia, dyslipidemia

\section{Introduction}

Childhood obesity is a serious global public health problem which has been increasing since last two decades. In the Philippines, we are facing the challenge of childhood obesity, particularly in urban areas. The national prevalence of childhood overweight and obesity in the Philippines has started to show an upward trend from 1993 to 2005; based on the Facts and Figures 2005 published by the Philippine Food and Nutrition Research Institute (FNRI), the prevalence of overweight, using a cutoff point of BMI $85^{\text {th }}$ percentile, has doubly increased from $2.4 \%$ to $4.8 \%$ (1993 to 2005) among adolescents (11-19 years). ${ }^{1}$ The national prevalence based on the seventh Nutritional Survey by FNRI did not show a significant change from 2005 to $2008(4.6 \%) .{ }^{2}$ A more recent local study (2009) reported a higher overall prevalence of overweight and obesity (21\%) among adolescents in Metro Manila. ${ }^{3}$ Those from upper socioeconomic status and studying in the private schools are at higher risk to be obese. ${ }^{4,5,6}$

Obese adolescents are at risk to develop metabolic syndrome (MetS), which is defined as having three out of five components: abdominal adiposity or central obesity, hypertension, hypertriglyceridemia, low level of high density lipoprotein-cholesterol (HDL) and hyperglycemia. ${ }^{7,8}$ Currently, there are different definitions of MetS in adolescents. In United States, the National Cholesterol Education Program-Adult Treatment Panel III (NCEP-ATP-III) criteria, ${ }^{9}$ modified for children and adolescents, and various other definitions were used. The International Diabetes Federation (IDF) in 2007 published a definition of MetS in children and

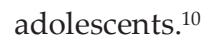

Studies have shown that the prevalence of MetS ranged from $8.9 \%$ in obese children to as high as $50 \%$ in severely
ISSN 0857-1074

Printed in the Philippines

Copyright (c) 2012 by the JAFES

Received September 22,2011. Accepted March 22, 2012.
Corresponding author: Sioksoan Chan Cua, MD

Address: Department of Pediatrics, College of Medicine and Philippine General Hospital, University of the Philippines,

Taft Avenue, Manila 1000

Telephone number: +632 5240892, +632 7277655

Fax number: +6327277655

E-mail address: sioksoan@gmail.com 
obese adolescents. ${ }^{11,12,13}$ Overweight and obese adolescents were shown to develop cardiometabolic complications at a young age, and also premature death in adulthood. ${ }^{14,15,16,17}$ In the Philippines, a study (2002) showed that one third of obese Filipino children and adolescents seen in a pediatric endocrine clinic had elevated total cholesterol and triglyceride levels, as well as low HDL-cholesterol levels. ${ }^{18}$ In another study (2000) of obese Filipino children with mean age of 10.8 years and BMI $>30$, the mean fasting insulin level was high at $34.8 \mathrm{uU} / \mathrm{ml}^{19}$

Chronic non-communicable diseases including diabetes, obesity, hypertension and heart diseases which were once thought to affect mostly developed countries, are now becoming the major health problems in Asia. ${ }^{12,20}$ These diseases have the greatest impact in low- and middleincome countries, where about three-fourths of deaths occur. So far, there has had no reported prevalence of MetS in Filipino adolescents. It is important to determine the prevalence of MetS in overweight and obese adolescents who are at risk to develop cardiometabolic diseases; the findings may provide insights for health professionals and policy-makers about the extent of these problems in young population.

\section{Objectives}

This study was done to determine the prevalence of MetS in overweight and obese Filipino adolescents based on the IDF definition. It also determined the prevalence of individual components of MetS, as well as hyperinsulinemia and insulin resistance.

\section{Methodology}

This study included a total of 350 overweight and obese adolescents (aged 10 to 18 years, 206 males and 144 females) who were referred to pediatric endocrine clinics in Metro Manila, Philippines from 2008 to 2010. Participants were included in the study with consent and assent. Adolescents who had pregnancy, known systemic diseases or other endocrine problems like thyroid dysfunction, Cushing syndrome, or took medications that altered blood pressure, glucose, or lipid metabolism were excluded from the study. The sample size was determined to achieve a $95 \%$ confidence interval and 0.05 margin of error based on a $35 \%$ prevalence rate of metabolic syndrome in overweight children and adolescents..$^{21,22}$

Height was measured in an upright position using a stadiometer and weight was determined using a standard weighing scale. The body mass index (BMI) is the weight in kilograms divided by the square of the height in meters. Waist circumference was measured at the midpoint between the lowest rib and the iliac crest, as recommended by WHO guidelines. ${ }^{23}$ Waist-height ratio is the waist circumference in centimeters divided by height in centimeters. Three seated blood pressure (BP) readings were obtained and the mean of these $\mathrm{BP}$ readings was used for statistical analyses. Blood was extracted for fasting blood glucose, lipid profiles and insulin determination.

Based on the World Health Organization (WHO) reference, when a BMI $z$-score for age and gender is $\geq+1$ to $<+2 \mathrm{SD}$, it is classified as overweight; when a BMI z-score is $\geq+2$ SD, it is obesity. ${ }^{24}$ Participants were considered as having MetS when they had at least three out of five clinical features: central obesity, hypertension, hypertriglyceridemia, low HDL level and hyperglycemia. In our study, the prevalence of MetS in the overweight and obese adolescents was determined based on the IDF definition ${ }^{10}$ (Appendix). Since there is no available national data of waist circumference in Filipino adolescents, abdominal adiposity or central obesity was based on a waist-height ratio of $\geq 0.5 .25,26,27,28$ Hyperinsulinemia was defined as fasting plasma insulin level $>15 \mu \mathrm{U} / \mathrm{ml} .{ }^{29}$ Insulin resistance was determined based on a homeostasis model assessment (HOMA) using the following formula: Insulin Resistance Index (IR) = fasting serum insulin $(\mu \mathrm{U} / \mathrm{ml})$ multiplied by fasting plasma glucose (mmol/L) and divided by 22.5. ${ }^{30}$ A HOMA-IR cutoff level of 3 in pediatric population was used to identify an insulin-resistance status. ${ }^{31}$

Descriptive statistics for continuous variables were expressed as the mean \pm the standard deviation. Chisquare and Fisher Exact Probability Test were used for correlation of metabolic syndrome with individual components. Statistical significance was taken at $\mathrm{p}<0.05$.

\section{Results}

\section{Characteristics of participants}

Among 350 participants, 206 (59\%) were males and 144 (41\%) females; 297 (85\%) were obese and 53 (15\%) were overweight. The age ranged from 10 to 18.8 years with a mean of $13 \pm 2.2$ years. The BMI ranged from 20 to 51.7, with a mean of $30.5 \pm 5.8$. There was no sex difference in most of the demographic and laboratory variables, except that males had larger waist circumference $(p=0.0004)$, waist-height ratio $(p=0.0009)$ and higher mean systolic BP $(p=0.0168)$.The clinical and biochemical characteristics of participants categorized by MetS were shown in Table 1.

\section{Prevalence of MetS}

According to the IDF definition, the overall prevalence of MetS in participants was 19\% (67/350). Among obese adolescents, 21\% (61/297) had MetS and among overweight adolescents, $11 \%(6 / 53)$ had MetS. In males, the prevalence of MetS was 20\% (41/206) and in females, it was $18 \%(26 / 144)$; there was no significant sex predilection $(\mathrm{p}=0.6817)$ (Table 1). In MetS group, participants were heavier and taller with greater BMI, waist circumference, waist-height ratio, $\mathrm{BP}$, triglyceride, fasting blood glucose (FBG), insulin and HOMA-IR levels, but lower HDL levels. 
Table 1. Clinical and biochemical characteristics of 350 participants

\begin{tabular}{|c|c|c|c|c|c|c|c|}
\hline \multirow[b]{2}{*}{ CHARACTERISTICS } & \multicolumn{2}{|c|}{ Total $(\mathrm{N}=350)$} & \multicolumn{2}{|c|}{ MetS Group ( $n=67)$} & \multicolumn{2}{|c|}{ Non-MetS Group ( $n=283)$} & \multirow[b]{2}{*}{ p-value } \\
\hline & No. & Percent & No. & Percent & No. & Percent & \\
\hline \multicolumn{8}{|l|}{ Sex } \\
\hline Males & 206 & $59 \%$ & 41 & $61 \%$ & 165 & $58 \%$ & 0.6817 \\
\hline \multirow[t]{2}{*}{ Females } & 144 & $41 \%$ & 26 & $39 \%$ & 118 & $42 \%$ & \\
\hline & Mean & SD & Mean & SD & Mean & SD & \\
\hline Age (year) & 13 & 2.2 & 13.8 & 2.3 & 12.9 & 2.1 & 0.0021 \\
\hline Weight (kg) & 76.1 & 21.0 & 89.4 & 23.6 & 72.9 & 19.0 & $<0.0001$ \\
\hline Height $(\mathrm{cm})$ & 156.5 & 10.5 & 161.4 & 9.7 & 155.3 & 10.3 & $<0.0001$ \\
\hline $\operatorname{BMI}\left(\mathbf{k g} / \mathbf{m}^{2}\right)$ & 30.5 & 5.8 & 33.9 & 6.9 & 29.7 & 5.2 & $<0.0001$ \\
\hline Waist circumference $(\mathrm{cm})$ & 96.1 & 13.7 & 103.8 & 16.0 & 94.3 & 12.5 & $<0.0001$ \\
\hline Waist-Height Ratio & 0.61 & 0.08 & 0.64 & 0.09 & 0.61 & 0.07 & 0.0031 \\
\hline \multicolumn{8}{|l|}{ Blood pressure $(\mathrm{mmHg})$} \\
\hline Systolic & 116 & 14 & 127 & 15 & 114 & 12 & $<0.0001$ \\
\hline Diastolic & 74 & 10 & 80 & 10 & 73 & 9 & $<0.0001$ \\
\hline \multicolumn{8}{|l|}{ Serum triglyceride } \\
\hline$(\mathrm{mmol} / \mathrm{L})$ & 1.38 & 0.7 & 2.16 & 0.93 & 1.20 & 0.47 & $<0.0001$ \\
\hline$(\mathrm{mg} / \mathrm{dl})$ & 122.2 & 61.8 & 191.1 & 82.6 & 105.9 & 41.6 & \\
\hline \multicolumn{8}{|l|}{ HDL-cholesterol } \\
\hline$(\mathrm{mmol} / \mathrm{L})$ & 1.23 & 0.2 & 1.09 & 0.21 & 1.26 & 0.18 & $<0.0001$ \\
\hline$(\mathrm{mg} / \mathrm{dl})$ & 47.5 & 7.8 & 42.0 & 8.1 & 48.8 & 7.2 & \\
\hline \multicolumn{8}{|l|}{ Fasting blood sugar } \\
\hline$(\mathrm{mmol} / \mathrm{L})$ & 5.4 & 3.2 & 7.2 & 6.2 & 4.9 & 1.8 & $<0.0001$ \\
\hline$(\mathrm{mg} / \mathrm{dl})$ & 97.3 & 57.6 & 130.9 & 110.5 & 89.9 & 32.5 & \\
\hline Serum insulin (uU/ml) & 23.4 & 18.1 & 31.3 & 24.3 & 21.5 & 15.8 & $<0.0001$ \\
\hline HOMA-IR & 5.2 & 4 & 7.7 & 5.3 & 4.6 & 3.4 & $<0.0001$ \\
\hline
\end{tabular}

\section{Components of MetS}

Based on the IDF definition, $14 \%$ of overweight and obese participants had 3 components, $5 \%$ had 4 components and none had 5 components. The remaining $81 \%$ participants had either $1(46 \%)$ or 2 components (35\%). The top 3 components of MetS were abdominal adiposity or central obesity, hypertension, hypertriglyceridemia, followed by low HDL and hyperglycemia. (Figure 1). There was no sex predilection in the prevalence of individual components $(\mathrm{p}>0.1)$.

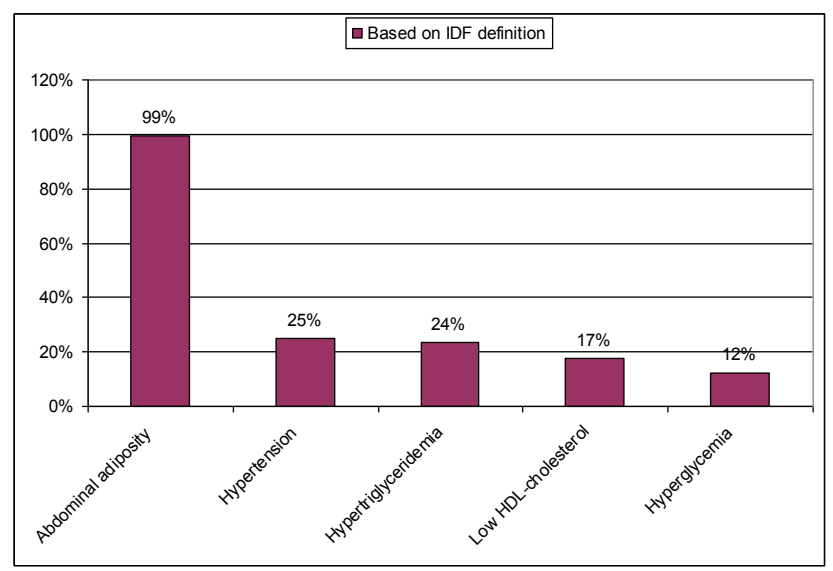

Figure 1. Occurrence of components of MetS among participants based on the IDF definition

\section{Hyperinsulinemia and insulin resistance}

Among overweight and obese adolescents, 67\% (233/350) had hyperinsulinemia (>15 uU/ml) and 70\% (244/350) had insulin resistance based on HOMA-IR $(\geq 3)$. Among those with MetS, the prevalence of hyperinsulinemia (79\%) and insulin resistance (90\%) was significantly higher (Table 2); the mean levels of serum insulin $(31.3 \mu \mathrm{U} / \mathrm{ml})$ and HOMAIR (7.7) were also high.(Table 1).
Table 2. Prevalence of hyperinsulinemia and insulin resistance in participants

\begin{tabular}{lccccc}
\multicolumn{1}{c}{ Variable } & \multicolumn{2}{c}{$\begin{array}{c}\text { All } \\
\text { participants } \\
(\mathbf{N = 3 5 0 )}\end{array}$} & \multicolumn{2}{c}{$\begin{array}{c}\text { MetS Group } \\
(\mathbf{n}=\mathbf{6 7})\end{array}$} & p-Value \\
\hline $\begin{array}{l}\text { Hyperinsulinemia } \\
\text { (>15uU/ml) }\end{array}$ & 233 & $67 \%$ & 53 & $79 \%$ & 0.0206 \\
$\begin{array}{l}\text { Insulin resistance } \\
\text { (HOMA IR } \geq 3)\end{array}$ & 244 & $70 \%$ & 60 & $90 \%$ & $<0.0001$ \\
\hline
\end{tabular}

\section{Discussion}

\section{Prevalence of MetS}

The rise in childhood obesity has contributed to the rising prevalence of the pediatric metabolic syndrome in developing countries. ${ }^{12}$ Using the IDF definition, the prevalence of MetS in Filipino overweight and obese adolescents (10 to $<19$ years) was $19 \%$; it was higher than the reported $8.9 \%$ in both Portuguese (10-20 years, median age 13.4 years) ${ }^{32}$ and French (10 to $<16$ years) overweight and obese adolescents, ${ }^{33}$ and also higher than $16.9 \%$ in obese Thai children and adolescents, ${ }^{34}$ but lower than $33.2 \%$ among overweight and obese adolescents (up to age 16 years) of multi-ethnic origin in Netherlands, $3523.3 \%$ and $40.4 \%$ among the extremely obese adolescents (12-18 years) in Italy and Germany, respectively. ${ }^{36}$

The risk of MetS increased as weight became heavier. In our study, the prevalence of MetS was higher in the obese than overweight adolescents. Similar finding was noted in other studies, including an Indian adolescent population. ${ }^{22}$

There was no consistent sex predilection noted in the studies of MetS in adolescents. Our study showed the prevalence of MetS was higher in males but the difference was not statistically significant. In a study of obese Bolivian children and adolescents, MetS was also found in larger proportion among males (40\%) than females $(32.2 \%)$, but not statistically significant (p-- 0.599). ${ }^{37}$ In 
obese Spanish pediatric population and Turkish obese adolescents, there were no differences by sex. ${ }^{38,39}$

\section{Components of MetS}

In this study, participants with MetS mostly had 3 components (14\%), followed by 4 components (5\%). Among extremely obese European adolescents, higher proportion of 4 components was reported: 16\% of Italian cohort and $28 \%$ of German cohort. ${ }^{36}$ Top 3 components of MetS in our study were abdominal adiposity, hypertriglyceridemia and hypertension; hyperglycemia had the lowest prevalence. Such findings were similar to the Portuguese study which reported that the waist circumference was the most prevalent component and hyperglycemia the least. ${ }^{32}$ Another review also showed that hyperglycemia had the lowest prevalence but high triglyceride level was the most frequent component of the MetS. ${ }^{40}$ The presence of cardiometabolic risks in obese adolescents should warrant early intervention to prevent further progression of complications.

\section{Hyperinsulinemia and insulin resistance}

Components of MetS included blood glucose but not insulin level. However, insulin resistance has been known as an important feature of MetS. The American Heart Association recommended adding fasting insulin determination to the evaluation of children at risk for insulin resistance. ${ }^{41} \mathrm{~A}$ longitudinal study demonstrated hyperinsulinemia in youth as a predictor of type 2 diabetes mellitus. ${ }^{42}$ In this study; fasting insulin and HOMA-IR levels were also determined. Although only $12 \%$ of participants had hyperglycemia, much more had hyperinsulinemia $(67 \%)$ and insulin resistance based on HOMA-IR (70\%). Our study showed that the association between variables (hyperinsulinemia and insulin resistance) and MetS was statistically significant. Detection of hyperinsulinemia and insulin resistance should alert the clinician to do intervention to prevent the progression to overt diabetes mellitus as well as MetS.

\section{Conclusion}

Overweight and obese adolescents are at risk to develop MetS. The prevalence of hyperinsulinemia and insulin resistance is high.

\section{Acknowledgments}

This study was approved by the Ethics Review Board and received a research grant (NIH 2008-01-30-02) from the National Institute of Health, and Dr. Artemio Jongco-Cosme Cagas in Pediatric Endocrinology and Metabolism Professorial Chair/ Faculty Grant. The author would like to acknowledge research assistants, Dr. Catherine Anne G. Pangilinan and Mrs. Gina Reyes, Professor Ma. Lourdes E. Amarillo and Ms. April Dyan R. Furia for the statistical assistance and the participants in the study.

Appendix. IDFdefinition of metabolic syndrome in adolescents ${ }^{10}$

\begin{tabular}{|c|c|c|}
\hline Component & Age 10 to $<16$ years & $\geq 16$ years \\
\hline $\begin{array}{l}\text { Central obesity } \\
\text { (waist circumference) }\end{array}$ & $\geq 90$ th percentile (or adult cut-off if lower) & $\begin{array}{l}>90 \mathrm{~cm} \text { for males and } \\
80 \mathrm{~cm} \text { for females based on Asia Pacific } \\
\text { criterion }\end{array}$ \\
\hline \multirow[t]{2}{*}{ BP } & \multirow[t]{2}{*}{$\geq 130 \mathrm{mmHg}$ systolic or $\geq 85 \mathrm{mmHg}$ diastolic } & $\geq 130 \mathrm{mmHg}$ systolic or $\geq 85 \mathrm{mmHg}$ diastolic \\
\hline & & $\begin{array}{l}\text { or on treatment for previously diagnosed } \\
\text { hypertension }\end{array}$ \\
\hline \multirow[t]{2}{*}{ Triglycerides } & \multirow[t]{2}{*}{$\geq 1.7 \mathrm{mmol} / \mathrm{L}(\geq 150 \mathrm{mg} / \mathrm{dl})$} & $\geq 1.7 \mathrm{mmol} / \mathrm{L}(\geq 150 \mathrm{mg} / \mathrm{dl})$ \\
\hline & & or on specific treatment for high triglycerides \\
\hline \multirow[t]{2}{*}{ HDL } & \multirow[t]{2}{*}{$<1.03 \mathrm{mmol} / \mathrm{L}(<40 \mathrm{mg} / \mathrm{dl})$} & In males: $<1.03 \mathrm{mmol} / \mathrm{L}(<40 \mathrm{mg} / \mathrm{dl})$ \\
\hline & & $\begin{array}{l}\text { In females: }<1.29 \mathrm{mmol} / \mathrm{L}(<50 \mathrm{mg} / \mathrm{dl}) \text { or on } \\
\text { specific treatment for low HDL }\end{array}$ \\
\hline Fasting blood glucose & $\begin{array}{l}\geq 5.6 \mathrm{mmol} / \mathrm{L}(\geq 100 \mathrm{mg} / \mathrm{dl}) \text { or known type } 2 \\
\text { diabetes mellitus }\end{array}$ & $\begin{array}{l}\geq 5.6 \mathrm{mmol} / \mathrm{L}(\geq 100 \mathrm{mg} / \mathrm{dl}) \text { or known type } 2 \\
\text { diabetes mellitus* }\end{array}$ \\
\hline
\end{tabular}

IDF: International Diabetes Federation

* If $F B G \geq 5.6 \mathrm{mmol} / \mathrm{L}(100 \mathrm{mg} / \mathrm{dL})$, OGTT is strongly recommended but is not necessary to define presence of MetS 


\section{References}

1. Food and Nutrition Research Institute, Department of Science and Technology. Philippine Nutrition: Facts and Figures, 2005. Taguig City: FNRI-DOST, 2007.

2. Food and Nutrition Research Institute, Department of Science and Technology. Seventh National Nutrition Survey 2008Anthropometric survey component: Pre-school children, adolescents, adults, pregnant and lactating mothers. Available at: http://www.fnri.dost.gov.ph/images/stories/7thNNS/anthrop/anthrop _preschool_adoles.pdf. Accessed August 22, 2010.

3. Chan-Cua, S, Amarillo MLE. Validity of body mass index based on self-reported weight and height in estimation of prevalence of overweight and obesity among adolescents. Phil J Pediatr. 2009; 57: 23-29.

4. Chan-Cua, S, Cuayo-Juico C, Bugayong-Regidor P, Guerrero M. Prevalence of overweight among boys in a Metro Manila private grade school. JAFES. 1995; 16-20.

5. Ley-Chua T, Cua S and Garcia RD. Correlation of body mass index with neck circumference, waist and hip circumference, waist-to-hip ratio and triceps skin fold thickness. Phil J Pediatr. 2003; 52: 117-125.

6. Florentino, RF, Villavieja GM, Lana RD. Regional study of nutritional status of urban primary school children. 1. Manila, Philippines. Food Nutr Bull.2002; 23: 24-30.

7. Eckel RH, Grundy SM, Zimmet PZ. The metabolic syndrome. Lancet. 2005; 365: 1415-1428.

8. Alberti KGMM, Zimmet PZ, Shaw JE. The metabolic syndrome - A new world-wide definition from the International Diabetes Federation Consensus. Lancet. 2005; 366: 1059-1062.

9. Cook S, Weitzman M, Auinger P, Nguyen M, Dietz W. Prevalence of a metabolic syndrome phenotype in adolescents: findings from the Third National Health and Nutrition Examination Survey, 1988-1994. Arch of Pediatr Adolesc Med. 2003; 157:821-827.

10. Zimmet P, Alberti KG, Kaufman F, et al. The metabolic syndrome in children and adolescents - an IDF consensus report. Pediatr Diabetes. 2007;8:299-306.

11. Csábi GY, Török K, Jeges S, et al. Presence of metabolic cardiovascular syndrome in obese children. Eur J Pediatr. 2000; 159: 91-4.

12. Kelishadi R. Childhood overweight, obesity, and the metabolic syndrome in developing countries. Epidemiol Rev. 2007; 29: 62-76.

13. Weiss R, Dziura J, Burgert $\mathrm{T}$, et al. Obesity and the metabolic syndrome in children and adolescents. N Engl J Med. 2004; 350: 23622374.

14. Dietz WH. Health consequences of obesity in youth: Childhood predictors of adult disease. Pediatrics. 1998; 101(3 Pt 2): 518-25.

15. Sorof J, Daniels S. Obesity Hypertension in Children, A Problem of Epidemic Proportions. Hypertension. 2002; 40: 441-447.

16. Franks PW, Hanson RL, Knowler WC, Sievers ML, Bennett PH, Looker HC. Childhood obesity, other cardiovascular risk factors, and premature death.N Engl J Med. 2010; 362: 485-93.

17. Reilly JJ, Kelly J. Long-term impact of overweight and obesity in childhood and adolescence on morbidity and premature mortality in adulthood: Systematic review.Int J Obes (Lond). 2011; 35:891-8.

18. Chan-Cua, S; Regidor, P. Hyperlipidemia of obese Filipino children and adolescents (Abstract). Asia Pac J Clin Nutr. 2002; 11: S744.

19. Chan-Cua S, Bugayong-Regidor P. Fasting Hyperinsulinemia in Obese Children and Adolescents (Abstract). J Pediatr Endocrinol Metab. 2000; 13: S1241.

20. Florentino, Rodolfo. The burden of obesity in Asia: Challenges in assessment, prevention and management. Asia Pac J Clin Nutr. 2002; 11: S676-680.

21. Cruz ML and Goran MI. The Metabolic Syndrome in Children and Adolescents. Curr Diab Rep. 2004; 4: 53-62.

22. Singh R, Bhansali A, Sialy R, Aggarwal A. Prevalence of metabolic syndrome in adolescents from north Indian population. Diabet Med. 2007; 24:195-9.

23. World Health Organization. Waist circumference and waist-hip ratio: report of a WHO expert consultation, Geneva, 8-11 December 2008. Geneva: WHO Document Production Services, 2011.

24. de Onis M, Onyango AW, Borghi E, et al. Development of a WHO growth reference for school-aged children and adolescents. Bull World Health Organ. 2007; 85: 660-7.

25. McCarthy HD and Ashwell M. A study of central fatness using waistto-height ratios in UK children and adolescents over two decades supports the simple message - 'Keep your waist circumference to less than half your height'. Int of Obes (Lond). 2006; 30: 988-992.

26. Garnett SP, Baur LA, Cowell CT. Waist-to-height ratio: A simple option for determining excess central adiposity in young people. Int J Obes (Lond). 2008; 32: 1028-30.

27. Yan $\mathrm{W}, \mathrm{He} \mathrm{B}, \mathrm{Yao} \mathrm{H}$, et al. Waist-to-height ratio is an accurate and easier index for evaluating obesity in children and adolescents. Obesity. 2007;15: 748-752.

28. Sung RY, So HK, Choi KC, et al. Waist circumference and waist-toheight ratio of Hong Kong Chinese children. BMC Public Health. 2008; 8: 324.

29. Ten S, Maclaren N. Insulin resistance syndrome in children. J Clin Endocrinol Metab. 2004; 89: 2526-2539.

30. Matthews DR, Hosker JP, Rudenski AS, Naylor BA, Treacher DF, Turner RC: Homeostasis model assessment: Insulin resistance and beta-cell function from fasting plasma glucose and insulin concentrations in man. Diabetologia.1985; 28:412-419.

31. Tresaco B, Bueno G, Pineda I, et al. Homeostatic model assessment (HOMA) index cut-off value to identify the metabolic syndrome in children. J Physiol Biochem. 2005; 61: 381-8.

32. Braga-Tavares H, Fonseca H. Prevalence of metabolic syndrome in a Portuguese obese adolescent population according to three different definitions.Eur J Pediatr. 2010; 169: 935-40.

33. Druet C, Ong K, Levy Marchal C. Metabolic syndrome in children: Comparison of the International Diabetes Federation 2007 consensus with an adapted National Cholesterol Education Program definition in 300 overweight and obese French children. Horm Res Paediatr. 2010; 73: 181-6.

34. Iamopas O, Chongviriyaphan N, Suthutvoravut U. Metabolic syndrome in obese Thai children and adolescents. J Med Assoc Thai. 2011;94 Suppl 3:S126-32.

35. van Vliet M, von Rosenstiel IA, Schindhelm RK, et al. Identifying the metabolic syndrome in obese children and adolescents: Do age and definition matter? Curr Clin Pharmacol. 2009; 4: 233-8.

36. Lafortuna CL, Adorni F, Agosti F, et al. Prevalence of the metabolic syndrome among extremely obese adolescents in Italy and Germany.Diabetes Res Clin Pract. 2010; 88:14-21.

37. Caceres M, Teran CG, Rodriguez S, et al. Prevalence of insulin resistance and its association with metabolic syndrome criteria among Bolivian children and adolescents with obesity. BMC Pediatrics. 2008; 8:31.

38. Lopez-Capape M, Alonso M, Colino E, et al. Frequency of the metabolic syndrome in obese Spanish pediatric population. Eur J Endocrinol. 2006; 155:313-319.

39. Atabek ME, Pirgon O, Kurtoglu S. Prevalence of metabolic syndrome in obese Turkish children and adolescents. Diabetes Res Clin Pract. 2006; 72:315-21.

40. Moraes AC, Fulaz CS, Netto-Oliveira ER, et al. Prevalence of metabolic syndrome in adolescents: A systematic review.Cad Saude Publica. 2009; 25: 1195-202.

41. William CL, Hayman LL, Daniels SR, et al: Cardiovascular health in childhood: A statement for health professionals from the Committee on Atherosclerosis, Hypertension, and Obesity in the Young (AHOY) of the Council on Cardiovascular Disease in the Young, American Heart Association. Circulation: 106:143-160.

42. Zimmet PZ, Collins VR, Dowse GK, Knight LT: Hyperinsulinaemia in youth is a predictor of type 2 (non-insulin-dependent) diabetes mellitus. Diabetologia. 1992; 35: 534 -541. 